\title{
EXCAVACIONES EN LA ZONA MEGALITICA DE VIGUERA (LA RIOJA) Collado Palomero I. Campañas de 1986 y 1987
}

\author{
Carlos L. PEREZ ARRONDO* \\ Carlos LOPEZ DE CALLE*
}

\begin{abstract}
RESUMEN
El artículo da cuenta de los trabajos de excavación llevados a cabo durante 1986 y 1987 en el monumento megalítico de Collado Palomero I (Viguera, La Rioja), un sepulcro de apreciables dimensiones que ha proporcionado interesantes datos tanto en el aspecto arquitectónico -particularmente la morfología del conjunto y el complejo sistema constructivo del túmulo-como en lo que respecta a las fases funerarias de ocupación, deducidas de observaciones estratigráficas y tipología de materiales, que invitan a establecer unos limites entre el Neolitico final (fase de fundación y primer uso) y el inicio de la Edad de los Metales (fase de intrusión).

Plabras clave: 1. España, Valle del Ebro, La Rioja, Sierra de Cameros. I. Prehistoria, Neolitico-Bronce, Megalitismo.
\end{abstract}

This article gives on account of the dig's works put through during 1986 and 1987 in the megalithic monument of Collado Palomero I (Viguera, La Rioja). This is a great sepulchre that have provided a interesting information about the architectural aspect-especially for its morphology and the complex building system of the mound-as well as the successive funeral uses, which can infer from the stratigraphic observations and the typology of the artefacts. Thanks to this information we can suppose that the monument was built in the Last Neolithic and was used until the beginning of the Bronze Age.

Key-words: 1. Spain, Ebro Valley, La Rioja, Sierra de Cameros. I Prehistory, NeolithicBronze Age, Megalithismus.

* Departamento de Ciencias de la Antigüedad. Area de Prehistoria. Colegio Universitario de La Rioja (U. de Zaragoza). 


\section{INTRODUCCION}

Dentro del plan de investigaciones sobre el megalitismo en la zona de Cameros que lleva a cabo el Departamento de Ciencias de la Antigüedad (Area de Prehistoria) del Colegio Universitario de La Rioja (Universidad de Zaragoza), el monumento de Collado Palomero I, perteneciente al conjunto de Viguera, ha sido objeto de cuatro campañas de excavación. Las dos primeras (1982 y 1985), de las que se dio cuenta en las correspondientes memorias previas ${ }^{1}$-a las que remitimos para el conocimiento de aspectos como situación y descripción general del monumento- atendieron primordialmente al estudio del recinto cameral, expoliado desde antiguo, y a lo que se describió como intrusión tumular con elementos culturales campaniformes.

El presente artículo trata de ofrecer, de forma sucinta, los datos recuperados en la 3. ${ }^{a}$ y $4 .^{\text {a }}$ campañas (1986 y 1987), que amplían y modifican lo conocido, particularmente en lo que se refiere a la estructura del monumento y a sus primeras fases de ocupación.

Los trabajos de ambas campañas, basados en el método tradicional de coordenadas cartesianas, extracción en tallas artificiales y cribado minucioso de todas las tierras, fueron autorizados y subvencionados por la consejería de Educación, Cultura y Deportes de la Comunidad Autónoma de La Rioja²

La campaña de 1986 atendió primordialmente a la ampliación del corte iniciado el año anterior en los cuadros 8/C-D y 10/C-D-E con el fin de delimitar la zona de intrusión campaniforme allí detectada y alcanzar la base del monumento. Ante la aparición de datos que permitían sospechar la existencia de un nivel subyacente, se extendió la excavación a todo el cuadrante suroriental del túmulo, acotándose entonces un área de acceso a la cámara -cuya naturaleza y significado serán analizados más adelante- utilizada, al menos en parte, con fines sepulcrales (fig. 1).

\section{ESTRUCTURAS CONSTRUCTIVAS Y AJUARES}

A. El túmulo.

El túmulo de Collado Palomero I, de proporciones desacostumbradas para un ejemplar ubicado a una altitud que sobrepasa los 1.200 m. s.n.m., fue construido siguiendo un proyecto previo perfectamente determinado consistente en la alternancia de capas superpuestas de piedras y tierra. Quedaría elevado así un promontorio organizado en casquetes esféricos truncados y superpuestos, de una marcada com-

1. PEREZ ARRONDO, C.L., 1983: La cultura megalitica en la margen derecha del Ebro. I Coloquio de Historia de La Rioja. Cuadernos de Investigación, Historia. Vol. I. Logroño. pp. 51-63. PEREZ ARRONDO, C.L., 1986: Informe preliminar sobre las excavaciones arqueológicas en la zona megalitica de Viguera. II Coloquio de Historia de La Rioja, Tomo I. Colegio Universitario de La Rioja. Zaragoza. pp. 9-18.

2. Quede constancia aquí de nuestro agradecimiento al esfuerzo inestimable de J. Ceniceros, I. Barrios, P. Alvarez, J.M. Tudanca, J. Sánchez Prieto, J.A. Sanz Mosquera, C. San Miguel, J. Fandiño, S. López de Castro, S. Blanco, F.R. Barrio, C. Sáenz Preciado, J.A. Ilarraza, R. Moreno, A. Tejeiro, O. Martínez, J.A. Algobia y J.L. Sáez Bretón. Sin su probada capacidad de adaptación a las durísimas condiciones climatológicas en las que se desarrollaron las labores en ambas campañas, la excavación no hubiera sido posible. Ellos saben, mejor que nadie, que el aprecio personal no puede, ni probablemente debe, quedar reflejado en una nota a pie de página. 


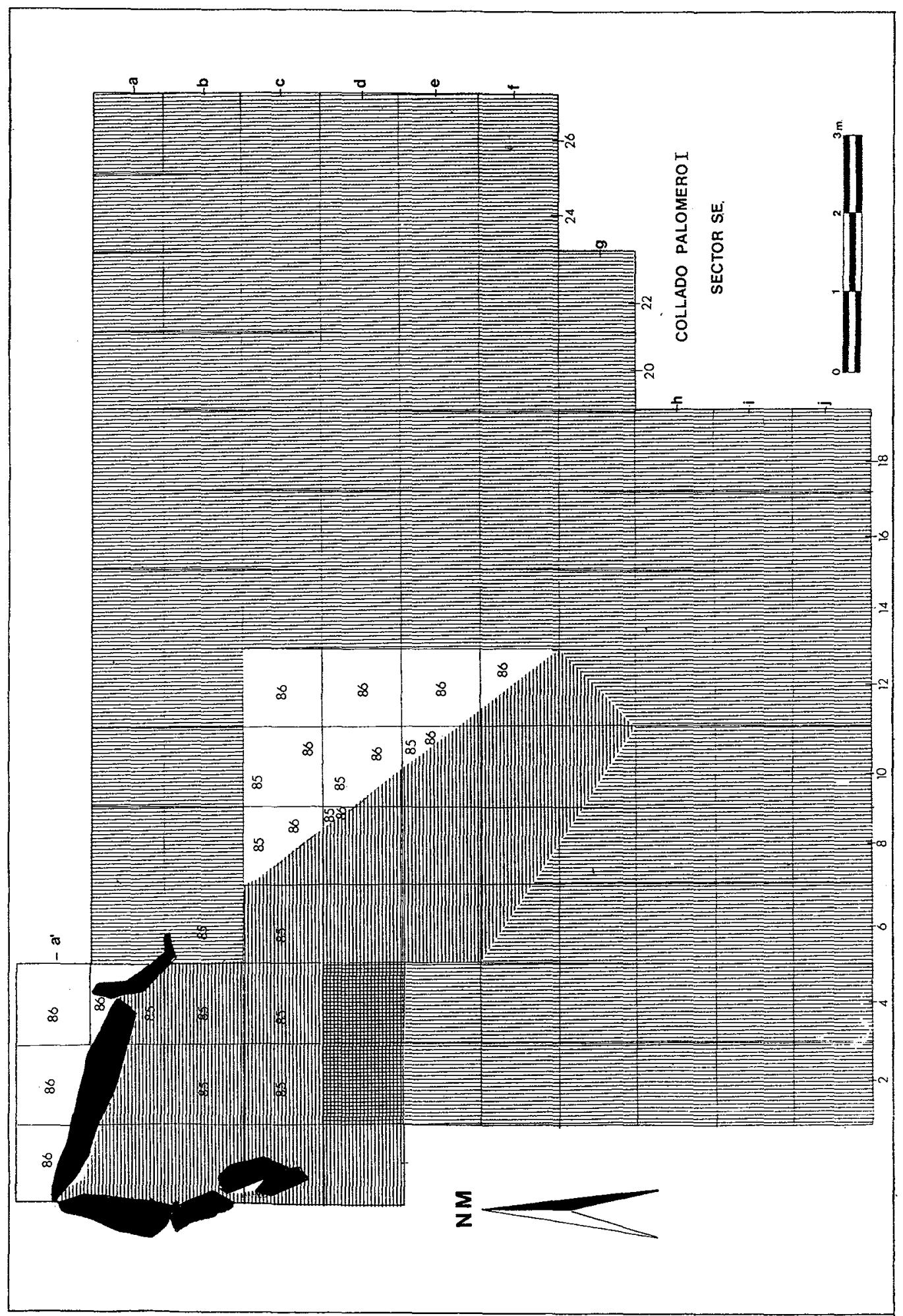

Fig. 1. Zonas excavadas en las diferentes campañas:

Trama horizontal: 1. ${ }^{\text {a Campaña (1982) }}$

85: 2. a Campaña (1985)

86: 3. ${ }^{\text {a Campaña (1986) }}$

Trama vertical: 4. ${ }^{\text {a Campaña (1987) }}$ 
pacidad, cuyo estado, a pesar de la lógica degradación en el transcurso del tiempo y el aprovechamiento de la cámara como cabaña de pastores en época moderna, permite su reconstrucción teórica (fig 2).

El corte estratigráfico obtenido en la zona sur-sureste (Bandas 1-2-4-6/ E-K) define claramente el método empleado en su construcción (fig. 3). La secuencia es la siguiente:

* Estrato superficial, formado por tierra vegetal y piedras sueltas de tamanos diversos.

* Estrato 1. Bloques de piedra de tamaño variable trabados entre sí y apoyados en ocasiones sobre lajas planas que evitan, al repartirse el peso sobre mayor superficie, su hundimiento en el estrato inferior. Forma el primer casquete que marca un diámetro máximo de entre 19 y $21 \mathrm{~m}$. Es factible que originalmente el diámetro fuera algo menor pues lógicamente la propia estructura inclinada ha favorecido el derrame de los bloques hacia la periferia. En la zona sur-sureste se pudo comprobar el añadido de un muro, muy probablemente de época moderna y sin ninguna duda posterior a la construcción del monumento, carente de relación estructural con él.

Los materiales recuperados en este estrato no tienen un contexto definido y deben proceder en su mayor parte de la violación y posterior empleo del dolmen como cabaña de pastores, fechada por los hallazgos numismáticos en el siglo XVII. Como dato interesante, que nos remite a los momentos de uso del conjunto en época prehistórica, citaremos la frecuente aparición de piezas soleras y volanderas de molinos barquiformes, fragmentadas en su mayor parte.

* Estrato 2. Tierra muy compactada que forma el segundo casquete esférico, con un diámetro de unos $17 \mathrm{~m}$. Los escasos restos recuperados se limitan a algunas esquirlas óseas y lascas de sílex.

* Estrato 3. Sus características son idénticas a las del estrato 1. Su mayor potencia y compacidad se deben a la preservación de agentes externos. Un dato interesante desde el punto de vista constructivo es el anillo de contención asentado sobre la base del monumento formado por bloques de dimensiones mayores que marca un diámetro de unos $14 \mathrm{~m}$. para esta segunda capa de piedras. Presumiblemente el primer casquete debió poseer un sistema de contención de características similares que no nos ha llegado. Arqueológicamente estéril.

* Estrato 4. Tierra fuertemente apelmazada de apariencia similar al estrato 2. Diámetro máximo de $11 \mathrm{~m}$. Sin material arqueológico, lo único reseñable es un fragmento de maxilar de herbívoro, muy probablemente un cérvido.

* Estrato 5. Bloques de grandes dimensiones. En otras zonas del dolmen se ha comprobado que su buzamiento es mucho más acusado que el de estratos anteriores de tal forma que cortaría a éstos hasta coincidir en altura con el estrato 1 en la parte lindante con la cámara. Estéril.

* Estrato 6. Tierra de color muy oscuro, base sobre la que se eleva el conjunto megalítico, anterior, por lo tanto, a su construcción. Alcanza su mayor potencia en la parte cercana a la cámara para servir de apoyo a los grandes bloques del estrato 5. Entre los restos recuperados en esta zona propiamente tumular, escasos pero bastante significativos, destaca la presencia de fragmentos cerámicos lisos, pequeños y en muy mal estado de 
EXCAVACIONES EN LA ZONA MEGALITICA DE VIGUERA (LA RIOJA)

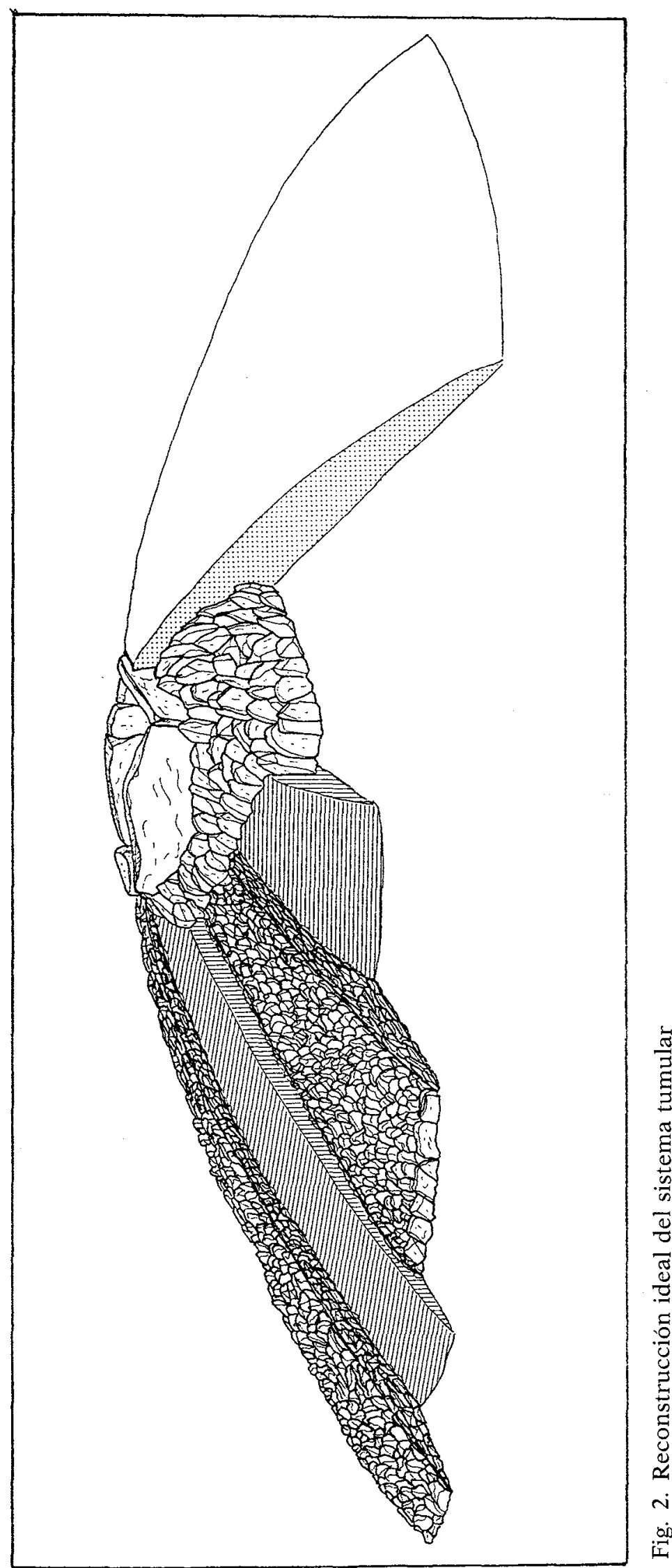




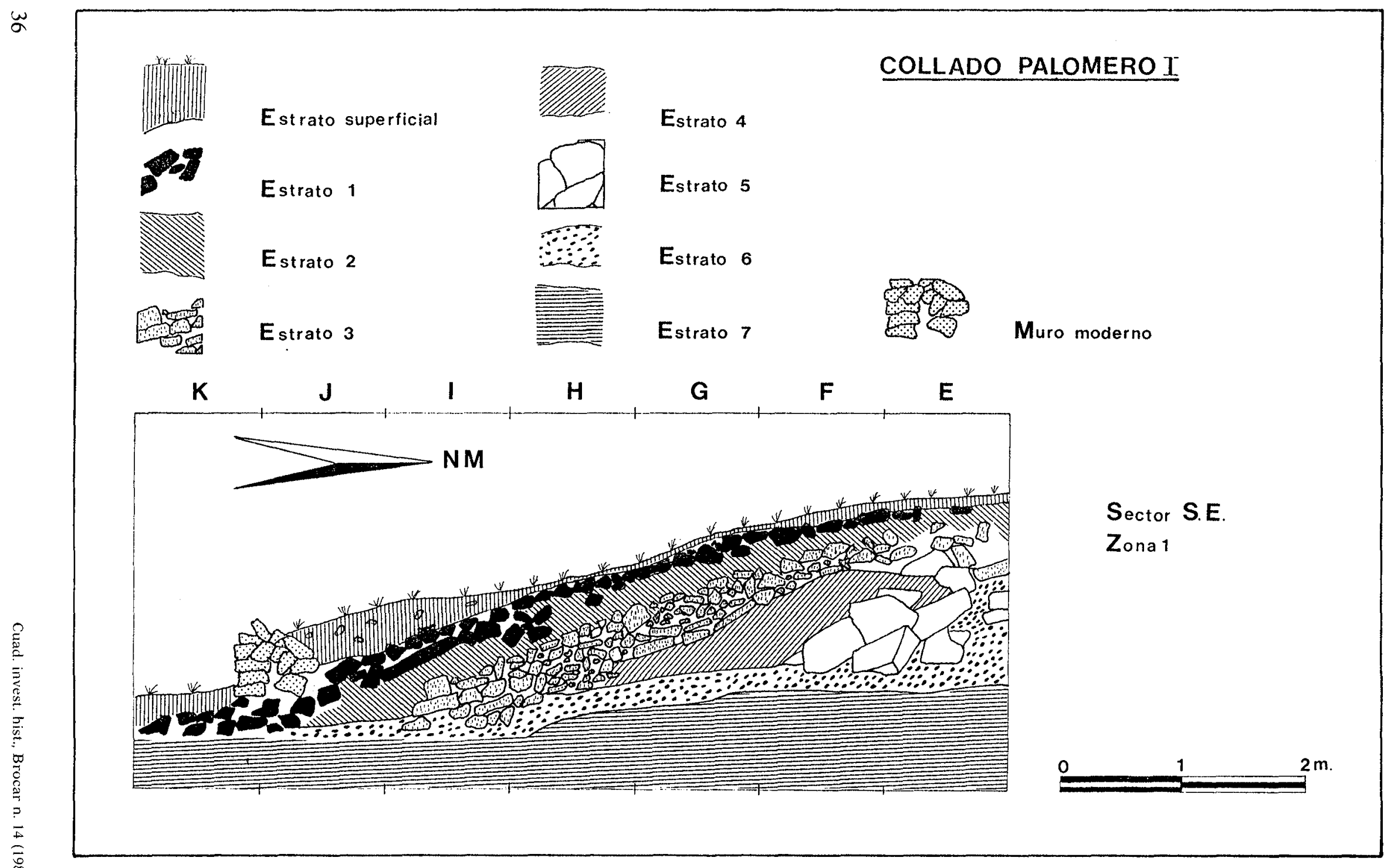

Fig. 3. Corte estratigráfico de la zona tumular 
conservación, algún fragmento de cerámica impresa (fig. 4: 1 y 2), restos óseos pertenecientes a herbívoros y una pobre industria lítica en la que lo único señalable es un segmento fragmentado de retoque abrupto.

* Estrato 7. Arcilla rojiza del terreno. Estéril.

$$
* * * *
$$

Esta ordenada forma de construcción se encontraba notoriamente alterada en las proximidades de la cámara. La caída de al menos un ortostato en la parte meridional (que yace en el fondo del recinto) provocó una quiebra de la cúspide del túmulo, circunstancia que debe explicar el hallazgo de materiales modernos en los aledaños de la cámara y la consiguiente pérdida de altura del túmulo. De la misma forma, al levantar las piedras del muro moderno, simplemente emplazado sobre los bloques más periféricos de la construcción tumular pero sin ninguna trabazón con ella, se encontraron fragmentos de vasijas torneadas y vidriadas y algunos clavos de hierro que no distorsionan el esquema estratigráfico general.

\section{B. La Zona de acceso.}

\section{Descripción.}

La ampliación de la cuadrícula a todo el cuadrante S.E. del dolmen permitió la demarcación de un área cuyas características no se ajustaban al método de casquetes esféricos superpuestos descrito anteriormente. En efecto, aunque exteriormente el aspecto de esta zona era similar a la del túmulo (sólo una pequeña planicie podría hacer sospechar su existencia antes de la excavación), los trabajos dieron como resultado la acotación de un área dentro de la cual los estratos 3 y 4 del túmulo -segunda capa de piedras y segunda capa de tierra apelmazada- eran sustituidos por un estrato único y de potencia considerable formado sólo por tierra. Los límites entre la estructura tumular y este amplio embudo venían marcados por un acusado buzamiento del estrato 3 (segunda capa de piedras) que disminuía su potencia hasta apoyarse en la base del monumento, formando una pared inclinada. Tal y como nos ha llegado, la superficie de esta zona es de unos $25 \mathrm{~m} .{ }^{2}$.

\section{Aspectos estratigráficos}

Habida cuenta de la extensión del área, los datos de potencia y superposición de estratos presentan variaciones dependiendo del cuadro que tomemos. Plantearemos, por lo tanto, un esquema teórico en el que las profundidades corresponden a los cuadros 10/C y 10/D, como ejemplo más significativo, restituyendo las informaciones obtenidas en la campaña de 1985:

* Estrato Superficial. $(\mathrm{X}=51-69)$. Tierra vegetal con piedras sueltas de tamaños variables.

* Estrato 1. $(\mathrm{X}=69-120)$. Similar al estrato 1 del túmulo, con piedras de diversas proporciones apoyadas sobre lajas planas. Inmediatamente debajo aparecen restos humanos en conexiones parciales. 
* Estrato 2. ( $\mathrm{X}=120-190)$. Tierra gris que va oscureciéndose a medida que profundizamos. En algunos cuadros se separaba del estrato subyacente por un manto irregular de piedras pequeñas a modo de empedrado. Restos humanos escasos e inconexos.

* Estrato 3. $(\mathrm{X}=190-212)$. Coincidente con el estrato 6 del túmulo en cuanto a profundidad, coloración y textura de las tierras. Existe, sin embargo, una notabie diferencia en cuanto a la mayor cantidad de testimonios arqueológicos recuperados aquí. Restos humanos inconexos y restringidos al cuadro $8 / \mathrm{C}$.

* Estrato 4. Arcilla rojiza, suelo natural. Estéril.

$$
\dot{*} \quad * \quad *
$$

El estudio de la disposición y ajuares acompañantes de los restos humanos permiten establecer en esta zona de acceso tres niveles ocupacionales distintos:

Nivel subyacente al conjunto funerario. En él se inscriben cinco estructuras artificiales (fig 5):

a. Alineación elíptica de piedras. En su interior fueron recuperados, en completo desorden, algunos restos óseos humanos, muy parciales. Presumiblemente se trata de una inhumación individual y secundaria. El ajuar acompañante consiste en un punzón óseo de base articular incompleto y una pieza lítica con señales de pulido, fragmentada, correspondiente probablemente a la parte volandera de un molino barquiforme. En sus aledaños se recogieron algunos fragmentos cerámicos de color anaranjado en un precario estado de conservación.

b. Hogar circular construido con piedras de pequeño tamaño apoyadas sobre el estrato natural de base. Abundantes restos de cenizas. Diámetro aproximado de unos $90 \mathrm{~cm}$.

c. Hogar de tendencia circular excavado en la arcilla del estrato de base y colmatado con piedras de tamaños diversos. Como en el anterior, fue recogido abundante material lígneo carbonizado. Diámetro aproximado de $1,30 \mathrm{~m}$.

d. Hogar de tendencia circular excavado en la arcilla de base, colmatado con piedras. Presencia de cenizas. Diámetro aproximado de $60 \mathrm{~cm}$.

e. Conjunto de piedras, algunas de ellas con rastros de fuego, que rellenan un hueco de pequeñas dimensiones. Sin cenizas.

En el interior del área que demarcaban estas estructuras se recogieron numerosos testimonios arqueológicos, mucho más abundantes que en la zona subyacente al túmulo.

El material lítico viene caracterizado por una mayoritaria presencia de restos de talla y en él destacan algunos núcleos de sílex, tres de ellos de notables proporciones y dos microlitos (segmentos) de retoque abrupto (fig. 6: 7). 


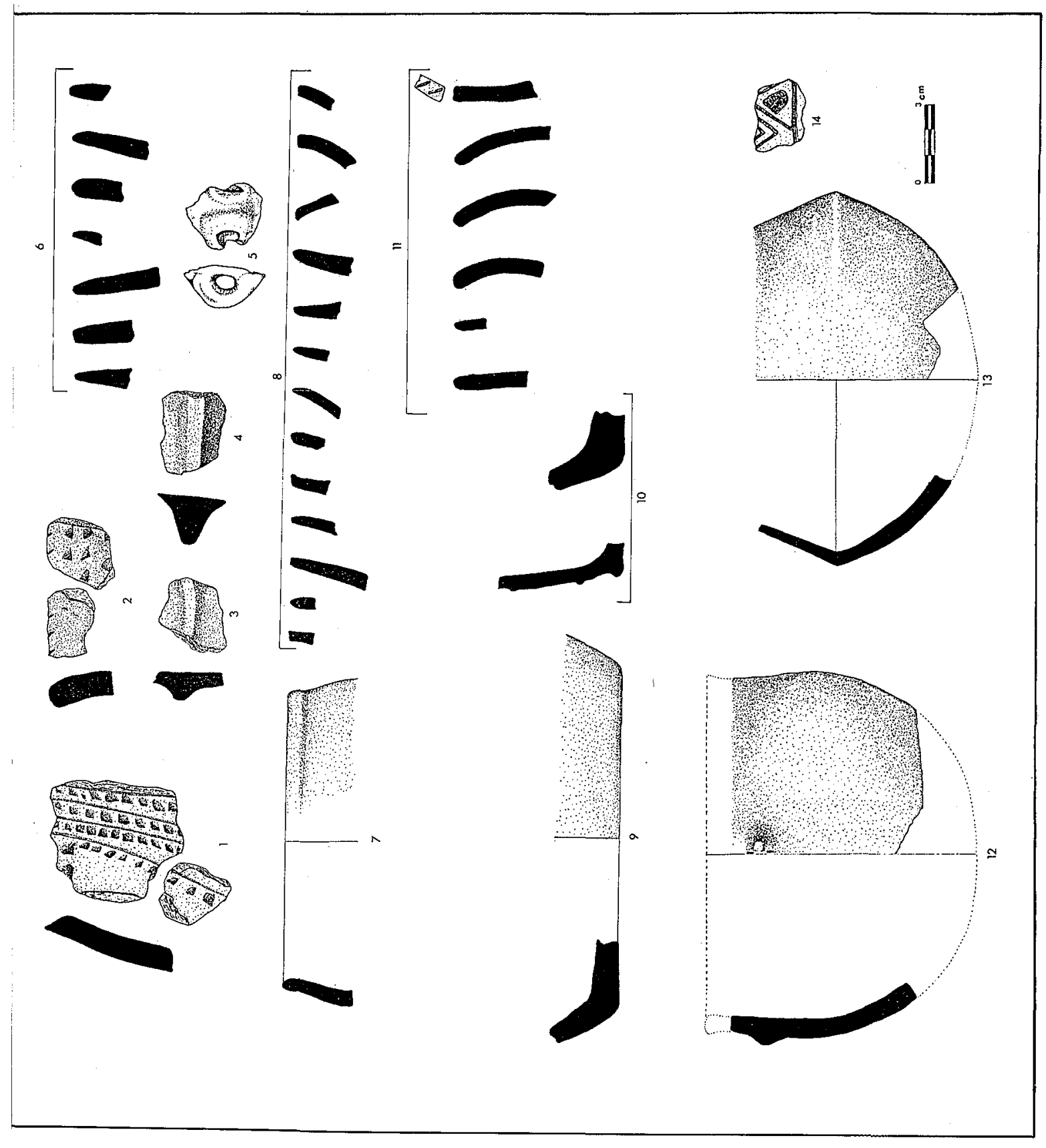




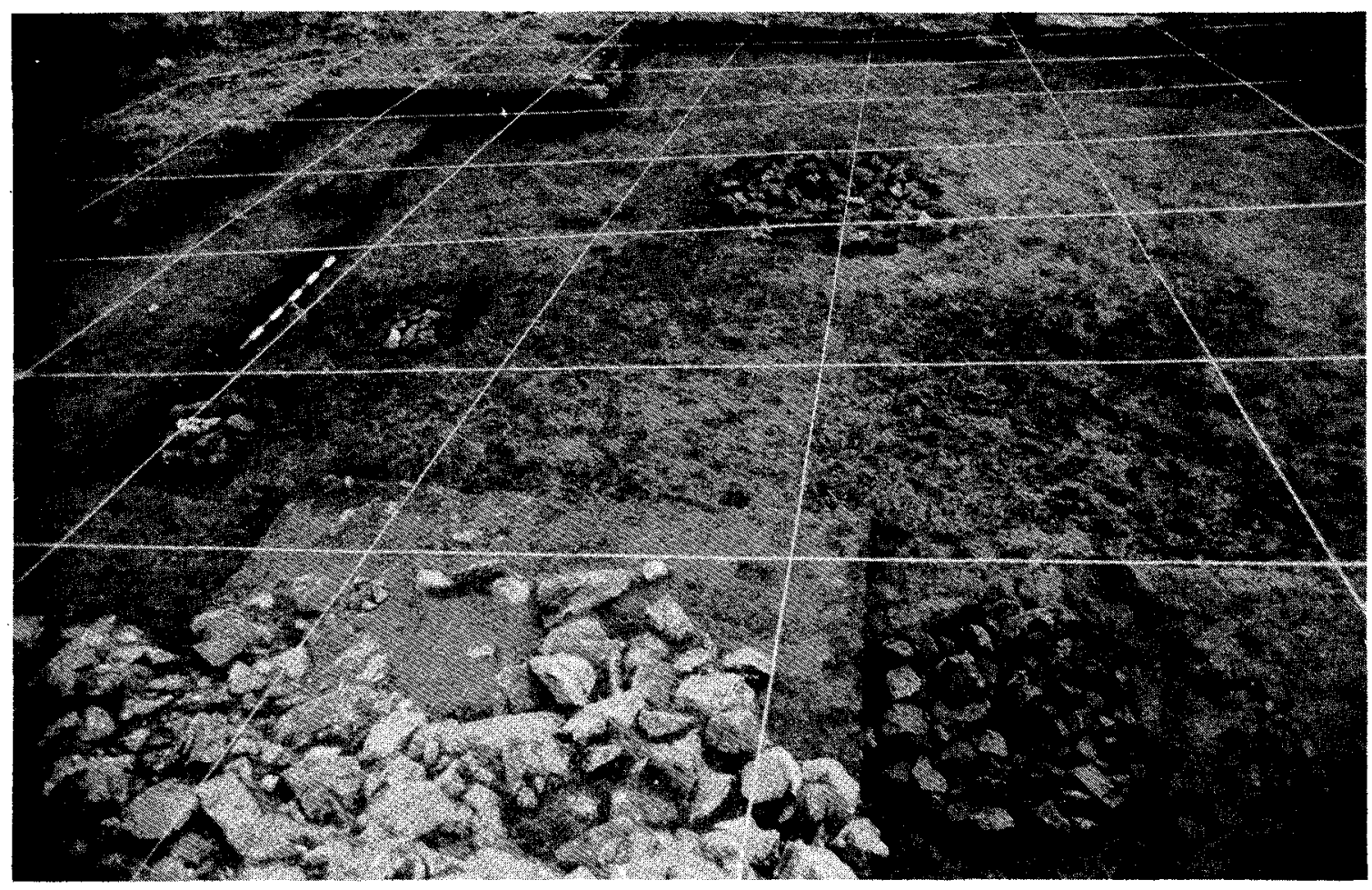

Foto 2. Situación de los hogares 
El material ceramológico apareció muy fragmentado y disperso. La morfología de la cerámica es bastante repetitiva: tendencia globular, bordes de formas cerradas simples o con cuello insinuado, en ocasiones vuelto, y algún ejemplar de pezón o asa pequeña perforada horizontalmente. Los únicos elementos decorativos quedan restringidos a cordones lisos aplicados, quizá en algún caso con funcionalidad de asa. Carencia absoluta de carenas marcadas y fondos planos. Las pastas son de dos tipos distintos: pastas porosas con desgrasante grueso y tonalidades anaranjadas que, a pesar de un acabado de buena calidad, aguantaron muy mal el elevado índice de humedad del estrato, y pastas muy decantadas, de paredes finas, color castaño oscuro y superficies alisadas, mucho mejor conservadas (fig 4: 3 a 8).

Hay que anotar igualmente una importante cantidad de restos óseos animales, desgraciadamente muy esquirlados. A pesar de ello, los dientes, particularmente abundantes alrededor y encima de las hogueras, permiten señalar la existencia de selenodontos (cérvidos), quizá pertenecientes a dos especies distintas.

Primer nivel funerario. Estratigráficamente bien diferenciado del anterior, sin embargo los elementos de cultura material, considerada la zona de acceso en su conjunto, no permiten una asignación tajante. De esta forma se recuperaron microlitos de retoque abrupto (segmentos, trapecios y triángulos) (fig 6: 8 a 12), una media luna con retoque a doble bisel (fig 6:114) y una punta de flecha de aletas incipientes con retoque plano invasor unifacial y restringido a la mitad de la pieza (fig. 6: 2). Del mismo modo, junto a cerámicas de tendencia formal semejante a las del nivel I, aparecieron tipos con cuellos ya perfectamente marcados e incluso formas carenadas. La industria ósea queda resumida en un fragmento distal de una espátula.

Hay que destacar, sin embargo, que en algunos cuadros (10/E, 12/F, 16/F, 14/E, 14/F) se recogieron restos humanos inconexos, alguno de ellos con señales de haber sido sometido a la acción del fuego, impregnados con ocre en ocasiones, junto a los cuales se encontraron microlitos de retoque abrupto, cuarzo cristalino en estado natural y algunas laminillas de esta misma materia.

Nivel funerario con restos campaniformes. La disposición de restos humanos y ajuar en el nivel superior de la zona de acceso mostraba un cierto orden. En la parte más alta fue exhumada la mayor parte del material, colocado sobre lajas planas de buen tamaño. Bajo estas losas se encontraron, parcialmente conectados, los restos óseos de un número indeterminado de individuos.

Los materiales pertenecientes a este nivel tienen como punto de referencia fundamental la cerámica campaniforme, representada en tres variedades: tipo ciempozuelos -un vaso completo, restos de una cazuela y varios fragmentos más quizá correspondientes a un segundo vaso-, puntillado geométrico -un vaso- y campaniforme internacional de bandas -dos fragmentos mínimos-. Como dato interesante señalaremos que el vaso puntillado geométrico contenía en su interior al de tipo ciempozuelos, lo cual aseguraría teóricamente su coetaneidad.

Entre el resto de las formas cerámicas asociadas con claridad a la intrusión campaniforme señalaremos fragmentos con cuellos desarrollados, fondos planos, labios digitados, carenas marcadas y pezones perforados verticalmente.

Junto a los restos humanos fue recogido un punzón de cobre de base simple, mientras que la industria lítica resulta escasa y poco representativa y no existe dato alguno en cuanto a adornos y material óseo trabajado. 


\section{OTROS DATOS DE CULTURA MATERIAL}

Al margen de los materiales hallados en estratigrafía, debemos detenernos en algunos objetos que bien por proceder de zonas alteradas, bien por su carácter de hallazgos superficiales, carecen de un contexto arqueológico definido, aun cuando en algún caso su tipología permita una asignación aproximada. Así, a los primeros momentos de ocupación de Collado Palomero I deben corresponder los microlitos geométricos; uno de ellos, fragmentado, presenta retoque a doble bisel y su correspondencia cronológica implica un problema específico del que hablaremos más adelante (fig. 6: 13). Más claro parece el carácter puramente campaniforme de dos nuevas cuentas cilíndrico-laminares de oro que elevan a nueve los elementos áureos del sepulcro, sin que, desafortunadamente, en ningún caso se haya podido establecer un conexión directa con las inhumaciones de este período ${ }^{3}$. Las puntas de retoque plano muestran una heterogénea tipología en la que quizá pueda rastrearse cierto escalonamiento temporal, siempre dentro de momentos tardíos en la ocupación del monumento (fig. 6: 1, 3 y 4). Reseñable, asimismo, es un fragmento de cerámica que presenta un motivo ornamental exciso (fig. 4: 14) localizado en el cuadro 8/B junto a restos humanos muy alterados. En este cuadro apareció igualmente una cuenta de material óseo perfectamente esférica, muy pulida, que muestra un pequeño orificio de súspensión elaborado por perforación unipolar. Para finalizar este apartado, señalaremos la presencia de una hachita pulida completa y un fragmento de talón de otro ejemplar, prácticamente en la superficie del túmulo.

\section{REFLEXIONES DE CONJUNTO}

No es nuestra intención interpretar en este informe preliminar el significado de materiales y estructuras de Collado Palomero I, sino, más bien, adelantar los puntos básicos sobre los que se apoya el estudio definitivo que nos ocupa ya en el momento presente.

\section{A. El túmulo.}

El sistema constructivo de superposición de capas de tierra y piedras no es desde luego inhabitual en las manifestaciones funerarias megalíticas de la Península Ibérica. A pesar de la escasa atención que han recibido tradicionalmente los túmulos de los sepulcros megalíticos y de que en contadas ocasiones se puede observar tan claramente el proceso constructivo, hallamos procedimientos afines en puntos distantes de la geografía peninsular, generalmente en relación con túmulos y cámaras de generosas dimensiones ${ }^{4}$ aunque, si hubiéramos de señalar concomitancias más

3. PEREZ ARRONDO, C.L. y LOPEZ DE CALLE, C., 1986: Aportaciones al estudio de las Culturas Eneoliticas en el Valle del Ebro. I: Elementos de adorno. Instituto de Estudios Riojanos. Historia/3. Logroño. pp. 134-139.

4. Consultar en las Actas de la Mesa Redonda sobre megalitismo peninsular. Asociación de Amigos de la Arqueología, Madrid, 1986: OLIVEIRA JORGE, V.: Problemática do Megalitismo do Norte de Portugal. pp. 34-36. BUENO RAMIREZ, P.: Megalitos en Extremadura. pp. 46-47. DELIBES DE CASTRO, G. y SANTONJA, M.: Aspectos generales del fenómeno megalítico de la Submeseta Norte. p. 147. 
estrechas, éstas parecen indicar cierta proximidad a soluciones adoptadas en algunas mámoas y dólmenes simples del norte de Portugal y Galicia, particularmente en lo que se refiere a la existencia de contrafuertes o entibados ciñendo los ortostatos de las cámaras ${ }^{5}$, sistema que, en versiones parecidas o más complejas, ha sido señalado en sepulcros vascos ${ }^{6}$ y meseteños. De cualquier manera, conviene plantearse hasta qué punto son significativas estas coincidencias puesto que, en principio, las soluciones a adoptar en la elevación de un túmulo que debe soportar las presiones de una construcción dolménica son bastante limitadas; las semejanzas entre áreas distintas podrían ser de hecho simples convergencias, circunstancia que además quedaría ratificada por el notable polimorfismo de los túmulos en conjuntos sepulcrales muy específicos en los que se supondría el mantenimiento de una tradición constructiva ${ }^{8}$.

\section{B. La zona de acceso.}

Los problemas que plantea la zona de acceso son múltiples y bastante complejos. Es evidente, en primer lugar, que no debe ser considerada como un corredor o, al menos, como un corredor tradicional, tanto por lo que toca a su estructura -carencia de losas laterales y diferencias en la morfología y dimensiones- como por lo que se refiere a una funcionalidad que, habida cuenta de los testimonios recuperados en sus límites, parece encajar mal con la consideración de simple área de tránsito utilizada eventualmente para fines sepulcrales. En repetidas ocasiones se han citado espacios, generalmente exteriores a las propias construcciones, denominadas como "atrios", "patios ceremoniales» o "antepórticos». Su extensión es muy amplia y se conocen ejemplares, más o menos sometidos a características parecidas, en muchos lugares: desde el Sudeste, Galicia o Portugal en la Península Ibérica, hasta Normandía o Irlanda en Europa9. Recientemente Mújịka y Peñalver han

5. CRIADO, F.; AIRA, M.J. y DIAZ FIERROS, F., 1986: La construcción del paisaje: Megalitismo y ecología. Sierra de Barbanza. Xunta de Galicia. Arqueoloxía/Investigación. Santiago. pp. 97. OLIVEIRA JORGE, V., 1984: Escavaçao da mamoa da Mina do Simao. Arqueología (G.E.A.P.), 8. Porto. pp. 7-9 y figs. 9 y 10.

6. MUJIKA, J.A. y PEÑALVER, X., 1987: Notes sobre el megalitisme a Euskal Herria. Cota Zero, 3. Vic. p. 17.

7. DELIBES DE CASTRO, G. y SANTONJA, M., 1986: El fenómeno megalitico en la provincia de Salamanca. Prehistoria y Arqueología, 1. Salamanca. p. 146.

8. La propia estación de Viguera puede ser un claro ejemplo de ello: el túmulo de Fuente Morena corresponde a un sistema más desordenado, en consonancia, quizá, con sus humildes proporciones; en Collado Palomero II parece haberse aprovechado, en parte del túmulo, un estrato natural de calizas, al igual que ocurre en Portillo de los Ladrones, sin componente megalítico, aunque en el resto del túmulo el sistema, en versión más simplificada, se asemeja bastante a Collado Palomero I. En este sentido se dirigen también los comentarios de Vítor Oliveira Jorge. OLIVEIRA JORGE, V., 1987: Megalitismo de Entre-Douro-e-Minho e de Tras-os-Montes (Norte de Portugal): conhecimientos actuais e linhas de pesquissa a desenvolver. El Megalitismo en la Península Ibérica. Madrid. pp. 116-117.

9. ALMAGRO, M. y ARRIBAS, A., 1963: El poblado y la necrópolis de Los Millares (Santa Fe de Mondújar, Almeria). Bibliotheca Praehistorica Hispana, vol III. Madrid. pp. 165-166. CRIADO, F; AIRA, M.J. y DIAZ-FIERROS, F., 1986: La construcción... ob. cit. p. 97. LEISNER, G. y LEISNER, V., 1951: Antas do Concelho de Reguengos de Monsaraz. Materiais para o estudo da cultura megalitica em Portugal. Reedición de la Unidade de Arqueología do Centro de Historia da Universidade de Lisboa. Lisboa, 1985. p. 27. VERRON, G., 1977: Un type de monuments funéraires classique dans le néolithique de Normandie. L'Architecture Mégalithique. Colloque du $150^{\circ}$ anniversaire de la Société Polimathyque du Morbihan. Vannes. p. 206. HERITY, M., 1974: Irish Passage Graves. Irish University Press. Dublin. p. 72. 


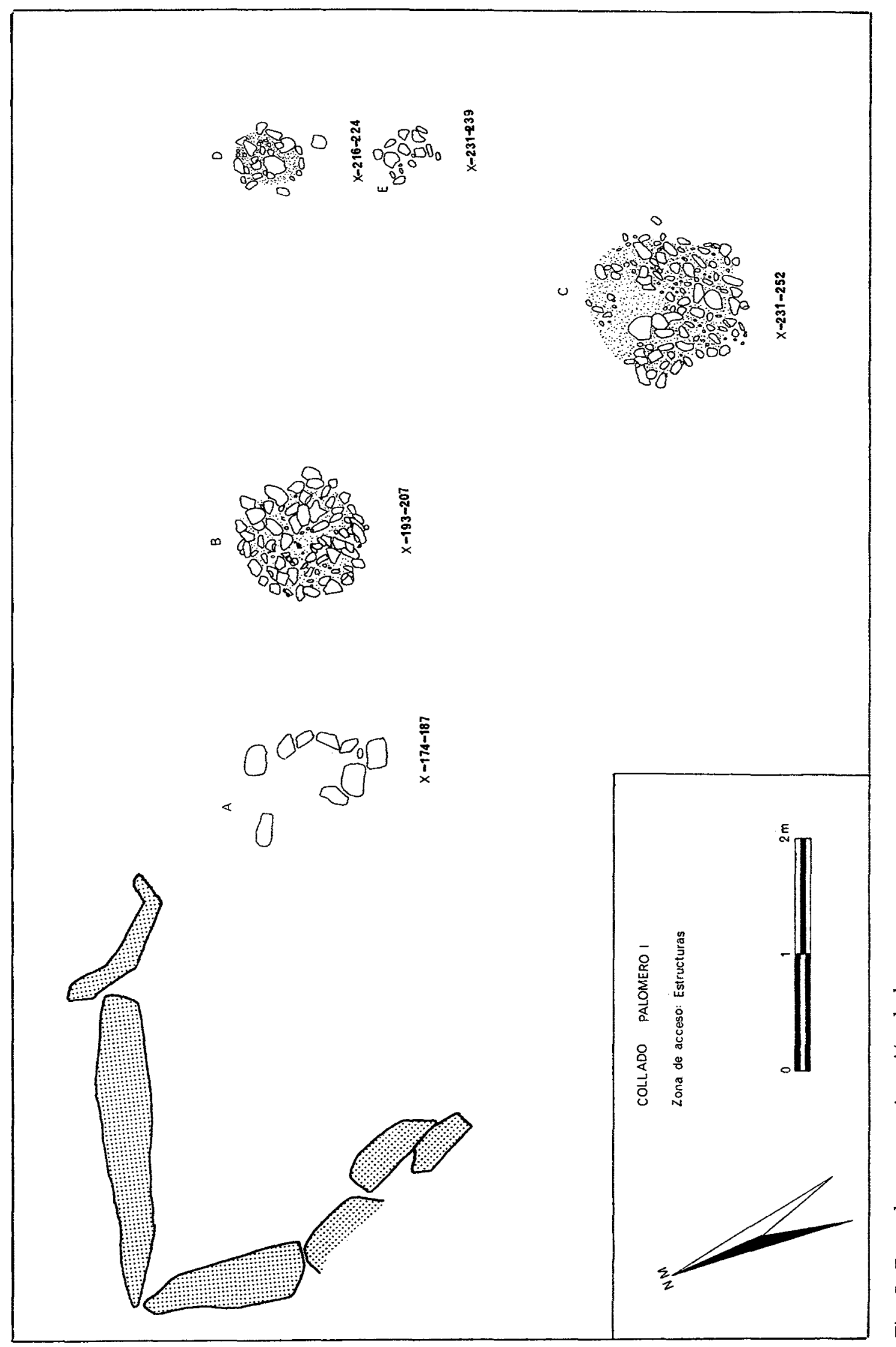

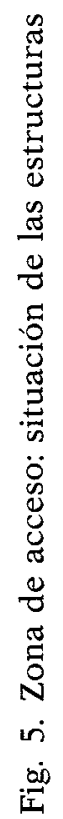


llamado la atención sobre los casos de la Chabola de la Hechicera y San Martín, en la vecina provincia de Alava, en donde aparecen estructuras que podrían ser perfectamente asimiladas a éstas. Se trata de espacios que unen la entrada del corredor con la periferia del túmulo, limitados por muretes en $\operatorname{seco}^{10}$. De cualquier forma, las diferencias con el caso de Collado Palomero I son manifiestas, pues en general se trata de sepulcros de corredor en los que éste no llega a tocar la periferia del túmulo, aunque conviene llamar la atención sobre su existencia porque la función de estos espacios bien pudo ser la de "área cultual específica", y no una simple solución arquitectónica en el trabado entre túmulo y corredor.

Un sistema muy interesante por sus posibles concomitancias es el descrito por Masters para ciertos long barrows, perfectamente ejemplificados en los casos de Lochhill y Slewcairn, en Inglaterra. Estas construcciones no megalíticas presentaban, según la interpretación de Masters, una fachada cóncava que delimitaba un área de antepórtico. En Slewcairn, la actividad en el interior de este espacio está atestiguada por el hallazgo de diversos objetos de sílex. En ambos casos el antepórtico fue bloqueado y las piedras del cairn ocultaron la primitiva apariencia de la estructura ${ }^{11}$. Entiéndase que la comparación con un lugar tan alejado geográficamente y con grupos de tradiciones constructivas no estrictamente megalíticas implica exclusivamente que pudieron adoptarse algunas soluciones parecidas en contextos distintos sin que haya que hacer necesaria alusión a relaciones de larga distancia. Así, sin negar la evidente excepcionalidad del caso en la zona, creemos muy improbable que Collado Palomero I sea un ejemplar único. Las dificultades que la detección de estructuras de este tipo conlleva, además de la carencia de excavaciones sistemáticas, permiten sospechar que determinados sepulcros de cámara simple de grandes dimensiones pueden contener sistemas parecidos ${ }^{12}$.

La definición de la zona de acceso como patio o antepórtico nos lleva a reflexionar sobre la primitiva apariencia del monumento que podría haber sido bien distinta a la que nos ha llegado. A pesar de la falta de indicios sobre una losa tapadera, las propias características arquitectónicas del monumento abogan por un sistema de acceso horizontal a la cámara. Sin embargo, en el estado que nos ha llegado el sepulcro, cada deposición comportaría la apertura y posterior reconstrucción de al menos la parte del túmulo por donde se debía acceder a la cámara, posibilidad que aunque no debe perderse de vista se antoja bastante complicada. Por ello es factible que el patio, al igual que ocurre en los ejemplos citados por Masters, se presentara, al menos en los primeros momentos de utilización del monumento, como una amplia entrada al aire libre, cubierta quizá con materiales ligeros, al estilo de los pitched-roofs británicos. La idea lleva implícita la posibilidad de importantes remodelaciones, de tal forma que la coraza exterior pudo ser un anadido posterior que clausuraba el monumento, de forma análoga a numerosos

10. MUJIKA, J.A. y PEÑALVER, X., 1987: Notes sobre... ob. cit. p.17

11. MASTERS, L., 1983: Chambered Tombs and Non-Megalitics Barrows in Britain. The Megalithic Monuments of Western Europe. Colin Renfrew Ed. Londres. pp. 103-104.

12. Puede resultar significativa la falta de indicios de corredor en algunos sepulcros con cámaras poligonales de la vecina provincia de Alava, tales como La Lastra, Campas de la Choza, Alto de la Huesera y Sorginetxe que, por sus dimensiones, debieron contar con algún sistema de acceso horizontal. ANDRES RUPEREZ, T., 1986: El megalitismo en el Pirineo Occidental. Actas de la Mesa Redonda sobre megalitismo peninsular. Asociación de Amigos de la Arqueología. Madrid. pp. 137-138. 


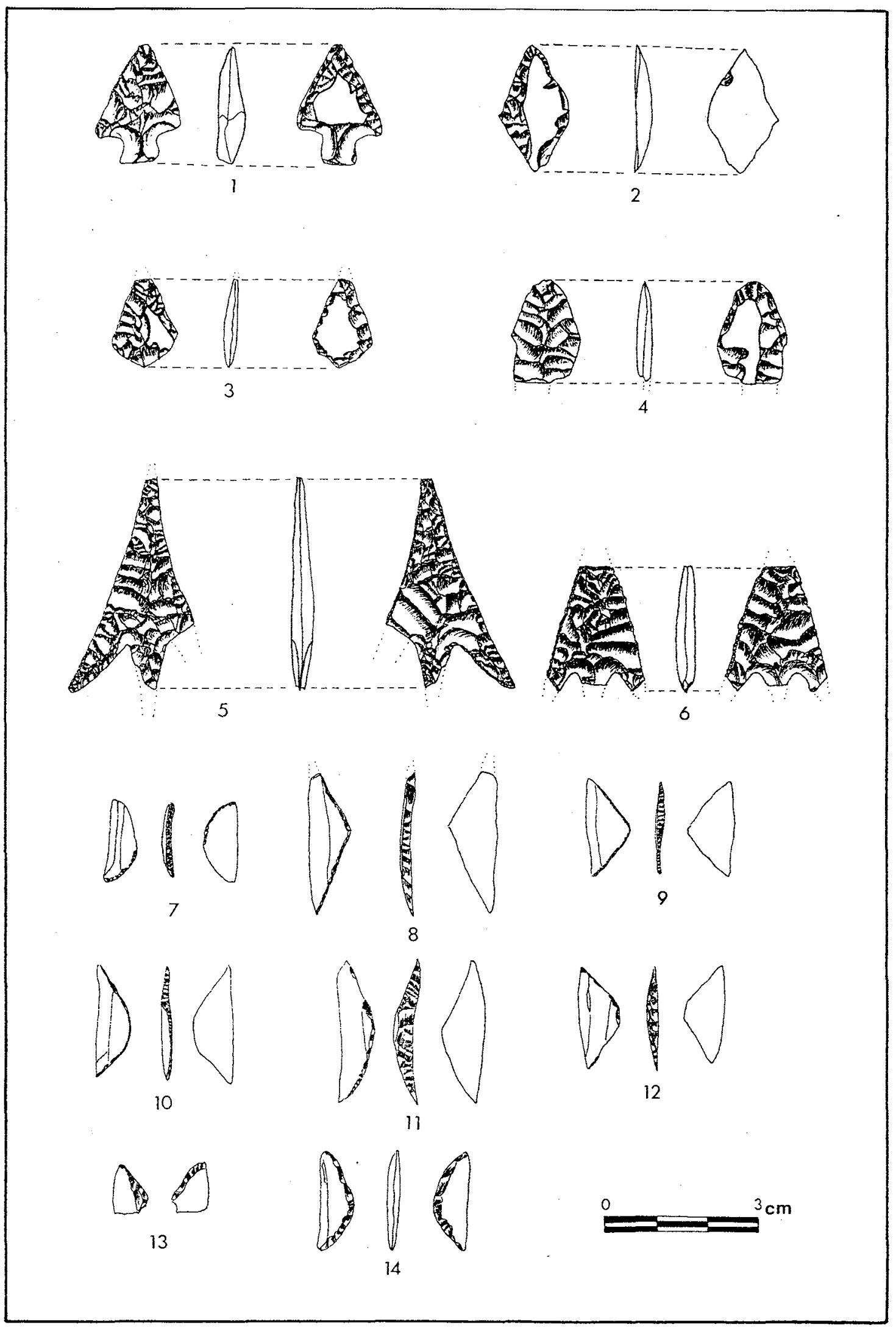

Fig. 6. Material lítico 
sepulcros de la fachada atlántica francesa, donde las reconstrucciones, añadidos y remodelaciones parecen ser una constante muy bien documentada ${ }^{13}$.

Parece comprobado que la construcción de sepulcros megalíticos vino precedida en algunos casos por actividades preparatorias de distinta naturaleza y significado $^{14}$ y no faltan ejemplos de hogares circulares de piedra en la base misma de los túmulos $^{15}$. No es menos cierto, sin embargo, que la utilización del fuego es una práctica muy constante y que, además de emplearse para preparar la base sobre la que se asientan los túmulos o como modelos rituales de fundación, también se han descrito en ocasiones hogares o restos de fuego de características parecidas que se realizaron tras la construcción del monumento ${ }^{16}$. En relación con estos hechos, una cuestión que debe quedar enunciada es la de la relación existente entre el estrato 6 , subyacente al túmulo, (en el que, según hemos dicho, fueron hallados algunos fragmentos cerámicos con decoración impresa, otros lisos, un segmento y escasos restos óseos de herbívoros) y el nivel de base de la zona de acceso, donde se enmarcan los hogares, la pequeña estructura funeraria, los numerosos testimonios líticos y cerámicos y los huesos de herbívoros. Dando por sentado que ambos niveles corresponden en términos culturales a un Neolítico avanzado, la disyuntiva que se plantea, en definitiva, es si el nivel de base del patio es anterior a la edificación del monumento, y por lo tanto una simple continuación del que hemos denominado estrato 6 del túmulo, o si, por el contrario, responde a momentos posteriores a su construcción.

La solución a tal dilema no es sencilla pues los datos obtenidos en la excavación no permiten afirmar categóricamente uno u otro extremo, aun cuando, como veremos posteriormente, parece claro que algunas actividades realizadas dentro de los límites del patio sí tuvieron lugar tras el levantamiento del sepulcro. Un análisis del material hallado bajo el túmulo y en la base del patio nos indica que en ambas zonas aparecen microlitos y restos de cérvidos, pero, en cuanto a los primeros, son elementos de una larga vida durante todo el Neolítico ${ }^{17}$ y los segundos, al margen de su nulo valor intrínseco como indicador cronológico, han aparecido también en Peña Guerra II y en el vecino sepulcro de Fuente Morena, formando parte de los conjuntos funerarios y no de niveles de fundación, y son conocidos igualmente en algunos dólmenes vascos, para los que se supone una finalidad de ofrenda alimenticia ${ }^{18}$, costumbre que podría tener un carácter, si no sistemático, al menos repetido en algunas ocasiones.

13. L'HELGOUACH, J. y LE ROUX, Ch-T., 1986: Morphologie et chronologie des grandes architectures de l'Ouest de la France. Le Néolithique de la France. Hommage a G. Bailloud. Démoule et Guilaine Dirs. París. pp. 189-191.

14. LUCAS PELLICER, R., 1986: Fenómeno megalítico: Estado de la cuestión. Actas de la Mesa Redonda sobre megalitismo peninsular. Asociación de Amigos de la Arqueología. Madrid. p. 12, nota 16. DELIBES DE CASTRO, G. y SANTONJA, M., 1986: Aspectos generales ... ob. cit. p. 147. DELIBES DE CASTRO, G. y SANTONJA, M., 1986: El fenómeno... ob. cit. p. 181.

15. En Pontevedra Arqueológica I. Pontevedra, 1984: PATIÑO GOMEZ, R.: Excavación de la mámoa 1 de Chan da Cruz (Vilaboa). pp. 17-44. y Excavación de la mámoa n. 1 de As Rozas (Campo Lameiro). pp. 45-74. MUJIKA, J.A. y PENALVER, X., 1987: Notes sobre... ob.cit. p. 19.

16. CAILlaUd, R. y LAGNEL, E., 1972: Le Cairn et le crematoire néolithiques de La Hogette à Fontenay-le-Marmion (Calvados). Gallia Préhistoire, 15, 1. París. pp. 78-180.

17. CAVA, A., 1984: La industria lítica en los dólmenes del País Vasco Meridional. Veleia, 1. Vitoria. pp. 95-106 y 130-134.

18. MUJIKA, J.A. y PEÑALVER, X., 1987: Notes sobre... ob. cit. p. 17 
Por otra parte, es preciso valorar el hallazgo, bajo el túmulo, de algunos fragmentos de cerámica impresa pertenecientes a una misma vasija, quizá una botella. La cerámica impresa no cardial, muy abundante durante el Neolítico medio oscense $^{19} \mathrm{y}$, por poner un ejemplo conocido, presente en los estratos bajos de La Vaquera (Torreiglesias, Segovia) ${ }^{20}$, se encuentra por desgracia muy mal documentada en áreas próximas pues los escasos ejemplares proceden de contextos revueltos o son hallazgos sueltos, de tal forma que sólo podemos indicar su carácter arcaizante, sin que estemos en disposición de matizar si indican una alta antigüedad, y consiguientemente una disparidad cronológica con el nivel de base del patio, o son simplemente los últimos ejemplos de una moda ornamental de amplia tradición ${ }^{21}$.

En cuanto a la posición de los hogares, su ubicación dentro de los límites del patio permite suponer alguna relación entre la entrada y estos restos de fuegos. Ciertamente, la asignación de los hogares a momentos anteriores a la edificación del monumento implica que los constructores habrían previsto su morfología, posibilidad que aunque remota no debe desdeñarse, pues la coincidencia podría estar justificada por esa "general, aceptada y comprobable relación de las orientaciones dolménicas con la salida del sol"22. Un hecho llamativo es el perfecto estado de conservación de los hogares, particularmente el detectado en los cuadros 12/C-D, colocado sobre el estrato estéril y no excavado en él como los otros dos. Ello nos hace pensar que fueron cubiertos con tierra en un momento no muy distante de su uso, quedando de esta foma preservados de la acción de agentes externos. Nada impide, por otra parte, que el uso del espacio que marca el patio haya sido periódico, es decir, que no todas las estructuras halladas en el interior respondan a una sola fase. Así, las actividades puramente inhumatorias evidenciadas en la base del patio debieron llevarse a cabo cuando el monumento estaba construido e incluso es factible que la cámara se encontrara ya totalmente repleta, como ocurre en múltiples sepulcros de corredor.

Con respecto a la detección de actividades funerarias en el patio, hemos expresado anteriormente la idea de que la estructura elíptica de piedras corresponde a una inhumación individual y secundaria. Los datos son particularmente interesantes, pues ponen sobre el tapete un tema que, por sus implicaciones en torno al modelo de las sociedades "megalíticas", resulta particularmente sugestivo. Recientemente, Delibes y Santonja expresan la opinión de que, aunque en muchas ocasiones se ha hecho referencia a la posibilidad de inhumaciones secundarias e individualizadas, no existen, al menos para una gran parte del megalitismo peninsular, datos que confirmen estos extremos, señalando igualmente que la idea está sólo justificada por la tópica consideración de un modelo de sociedades itinerantes ${ }^{23}$. Creemos sin embargo que los datos obtenidos en Collado Palomero indican en al menos un caso la existencia de una inhumación individualizada que parece ser secundaria. Aun en el supuesto de que hubiera habido una remoción posterior, la estructura en cuyo

19. BALDELloU, V., 1983: Conclusiones finales. (Cueva de Chaves, Bastaras, Huesca). Bolskan, 1. Huesca. pp. 137-148.

20. ZAMORA, A., 1976: Excavaciones en la cueva de La Vaquera (Torreiglesias, Segovia). Segovia. figs. 17 y 19.

21. La pieza más próxima es una botella aparecida en Cueva Lóbrega. Consultar, en este mismo volumen, CENICEROS, F.J. y BARRIOS, I.: Reinterpretación de las estratigrafias y ajuares arqueológicos de Cueva Lóbrega (Torrecilla en Cameros, La Rioja).

22. ANDRES RUPEREZ, T., 1986: El megalitismo... ob. cit. p. 139.

23. DELIBES DE CASTRO, G. y SANTONJA, M., 1986: El fenómeno... ob. cit. p. 186. 
interior fueron recuperados los restos humanos resulta excesivamente pequeña para contener a un individuo en conexión, aunque éste hubiera sido depositado en la típica posición fetal. Como material asociado, indudablemente con un carácter de ajuar u ofrenda, sólo se halló un punzón óseo de base articular, presumiblemente de cronología neolítica, ${ }^{24}$ y un fragmento de una pieza volandera de un molino que quizá fue simplemente utilizada como otra piedra más de la estructura. El hecho pudiera tener su correspondencia en la estructura hallada por C. Morán en el dolmen de Terradillos (Salamanca). Sin embargo, y como es habitual en los dólmenes salmantinos, la acidez del suelo ha impedido la conservación de los posibles testimonios óseos ${ }^{25}$.

Aunque parece clara la intención de enfatizar el carácter individual del enterramiento, sería temerario extraer conclusiones que afectan al esquema social o económico de un grupo, no sólo por lo aislado del caso detectado en Collado Palomero I, sino porque carecemos de bases que confirmen una estricta relación entre módulos funerarios, de los que sólo conocemos su apariencia externa pero no su significado profundo, y unos modelos socioeconómicos que nos permitirian, en el mejor de los casos, elegir entre sociedades paritarias y jerarquizadas, o entre grupos itinerantes y grupos establecidos territorialmente, léase comunidades ganaderas o agrícolas, simplificaciones de las que quizá no se pueda huir por el momento, pero que evidentemente no nos pueden contentar.

Como hemos dicho anteriormente, parece que el patio fue usado como receptáculo funerario, a causa, presumiblemente, de la colmatación. del recinto cameral. Ello nos hace pensar que antes de su cerramiento se produjo un relleno parcial en la zona de acceso que acogería inhumaciones, probablemente secundarias también, a las que corresponderían los restos descritos anteriormente en los cuadros $10 / \mathrm{E}$, $12 / \mathrm{F}, 14 / \mathrm{E}, 14 / \mathrm{F}$ y 16/F. En un momento más avanzado, pero imposible de precisar con exactitud, el sepulcro se vería recrecido con la coraza exterior que clausuraba esta entrada y protegía los últimos restos depositados. Ello no invalida la posibilidad de que el patio o incluso la cámara fueran utilizados más tardíamente, aunque ya con un carácter eminentemente intrusivo. Así se explica que en la zona donde aparecía el conjunto campaniforme, dentro de los límites del patio pero en una posición bastante superficial, la coraza exterior se encontrara notoriamente alterada, de tal forma que la ordenada disposición de las piedras en capas, aun siguiendo un esquema parecido, dejaba ver una falta de continuidad bastante clara.

24. Aunque el valor cronológico de los punzones de base articular es muy restringido, su aparición es constante en yacimientos funerarios con niveles neolíticos claros como Peña Guerra II, San Martín o El Miradero. RODANES VICENTE, J.M. 1987: La industria ósea prehistórica en el valle del Ebro. Neolitico - Edad del Bronce. Arqueología y Paleontología, 4. Zaragoza. pp. 68-72. PEREZ ARRONDO, C. L. y RODANES VICENTE, J.M., 1979: Excavaciones en la zona dolménica de Peña Guerra (Nalda, La Rioja). Cuadernos de Investigación (Geografía e Historia), T. 5 fasc. 2. Logroño. pp. 75-94. BARANDIARAN, J.M. y FERNANDEZ MEDRANO, D.: Excavación del dolmen de San Martín (Laguardia, Alava). Investigaciones Arqueológicas en Alava, 1957-1968. Vitoria. pp. 143-173. DELIBES DE CASTRO, G.; ALONSO DIEZ, M y GALAN MORALES, R., 1986: El Miradero: un enterramiento tardoneolitico de Villanueva de los Caballeros (Valladolid). Estudios en Homenaje al Dr. A. Beltrán. Zaragoza. pp. 227-236.

25. MORAN, C., 1935: Excavaciones en dólmenes de Salamanca y Zamora. Junta Superior del Tesoro Artístico, 135. Madrid. pp. 5-9. DELIBES DE CASTRO, G. y SANTONJA, M., 1986: El fenómeno... ob. cit. pp. 185-186. 


\section{La ocupación del monumento.}

Del estudio de la estratigrafía y de los materiales hallados fuera de contexto, se pueden aventurar las siguientes fases de ocupación del monumento:

- Fase de fundación, anterior a la construcción del monumento, encuadrable en un Neolítico final. El ajuar, en el que destaca la presencia de cerámicas impresas y un segmento de círculo, resulta muy pobre y sólo cabe reseñar la posibilidad de que, como se ha señalado en múltiples ocasiones, corresponda a actividades preparatorias, quizá de tipo ritual ${ }^{26}$.

- Fase de utilización primaria del sepulcro, encuadrable en un Neolítico final más avanzado y rastreable en la base del patio de entrada del monumento. La industria lítica viene marcada por la abundancia de restos de talla y la presencia de tres segmentos de círculo con retoque abrupto. Las cerámicas, de morfologías muy simples y tendencia globular, vienen en ocasiones decoradas mediante verdugones lisos aplicados y pezones perforados horizontalmente. La existencia de hogares y la abundancia de restos óseos pertenecientes a grandes herbívoros, invitan a caracterizar el recinto como área de actividad ritual, en posible relación con las desaparecidas inhumaciones de la cámara.

- Fase de utilización tardía, sin correspondencia estratigráfica pero rastreable en las tipologías de algunos materiales líticos, correspondiente a un Calcolítico temprano. Su asignación cronológica y cultural está basada en el supuesto de la anterioridad de las puntas foliformes y de aletas en apéndice sobre las de pedúnculo y aletas desarrolladas ${ }^{27}$. Son piezas conocidas y muy bien estudiadas en el País Vasco, y elementos de características más o menos parecidas son tomados como punto referencial del Calcolítico temprano en la Meseta ${ }^{28}$.

Más complicado resulta asignar una cronología específica para los microlitos con retoque a doble bisel, pues aunque son conocidos desde momentos muy tempranos en el Neolítico mediterráneo, también se han recuperado en estratos claramente calcolíticos, como en el yacimiento bajoaragonés de Costalena $^{29}$. Son elementos desconocidos prácticamente dentro de contextos megalíticos próximos ${ }^{30}$ sin que se pueda señalar ninguna relación con la

26. Vide nota num. 14

27. UTRILlA MIRANDA, P., 1982: El yacimiento de la cueva de Abauntz (Arraiz, Navarra). Trabajos de Arqueología Navarra, 3. Pamplona. pp. 238-244 y 326-330.

28. CAVA, A., 1984: La industria... ob. cit. pp. 107-116. DELIBES DE CASTRO, G. y SAN TONJA, M., 1986: El fenómeno... ob. cit. pp. 201-204

29. BARANDIARAN, I. y CAVA, A., 1981: Epipaleolitico y Neolitico Antiguo en el abrigo de Costalena (Bajo Aragón). Bajo Aragón Prehistoria, III. Zaragoza. p. 15.

30. En el vecino sepulcro de Fuente Morena (Montalbo, La Rioja), durante la excavación de 1986 apareció un único segmento con retoque a doble bisel dentro de un conjunto material que parece indicar una notable antigüedad (geométricos de retoque abrupto y formas cerámicas que repiten la tendencia de las fases más antiguas de Collado Palomero I). PEREZ ARRONDO, C.L. y LOPEZ DE CALLE, C., 1987: Excavaciones en el monumento de Fuente Morena (Montalbo en Cameros, La Rioja). Informe preliminar. Instituto de Estudios Riojanos. Berceo. (en prensa). 
aparición del retoque plano, con el que pudieron convivir pero del que no parecen ser un antecedente claro ${ }^{31}$. Llamaremos la atención sobre su presencia en el yacimiento riojano de Muro de Aguas, donde Beguiristain les señala igualmente un carácter eneolítico a pesar de la ausencia total de piezas de retoque plano dentro del conjunto ${ }^{32}$.

- Fase de intrusión, con cerámica campaniforme incisa, puntillada geométrica e internacional, un punzón metálico, recipientes de fondos planos, formas cerámicas con cuellos destacados, pezones perforados verticalmente $y$, en ciertos casos, carenas marcadas, todo ello dentro de una zona bastante delimitada y restringida a los cuadros 10-C y 10-D y algunos cuadros próximos. Encuadrables en un momento Eneolítico-Bronce Antiguo, es poco probable que las inhumaciones sean consecuencia de una deposición simultánea al estilo de la conocida en la fosa de La Atalayuela (Agoncillo, La Rioja) ${ }^{33}$. El campaniforme internacional, representado por dos fragmentos muy pequeños, debería anteceder a las otras dos especies cerámicas, halladas en íntima conexión. Junto a estos materiales recuperados en estratigrafía, es preciso llamar la atención sobre las nueve cuentas y apliques de oro y las tres puntas de pedúnculo y aletas, materiales que suelen acompañar muy habitualmente al material campaniforme ${ }^{34}$, pero que en este caso proceden de contextos revueltos o superficiales. Ello invita a conjeturar que las inhumaciones campaniformes no se restringieron exclusivamente a la zona descrita más arriba, sino que ocuparon otros espacios del monumento, probablemente la misma cámara, con un carácter intrusivo. Es lícito, por lo tanto, imaginar que la última fase de ocupación del monumento, bastante intensa al parecer, implicó un uso dilatado cronológicamente, cuyo límite final no es fácil de precisar habida cuenta de la tipología, quizá muy tardía, de algunos recipientes cerámicos. En este sentido, no puede valorarse como decisivo el hallazgo de cerámica decorada mediante excisión que, en sí, sólo implica una nueva modalidad decorativa, conocida por otra parte sobre un vaso campaniforme en Peña Guerra II. La escasa superficie conservada en el fragmento al que nos referimos, hallado también fuera de contexto, impide hacer más precisiones.

$$
* \quad * \quad * \quad *
$$

Asistimos, pues, en Collado Palomero I a ocupaciones multiperiódicas, probablemente intermitentes y acumuladas a lo largo de un amplísimo período, circunstancias que según los testimonios aportados por los otros yacimientos de la estación son exclusivos en este sepulcro. Así, Fuente Morena, Portillo de los Ladrones y Collado Palomero II sólo parecen haber sido empleados como receptáculos funera-

31. CAVA, A., 1984: La industria litica... ob. cit. p. 100.

32. BEGUIRISTAIN, M.A. y SOLE SEDO, J., 1983: Un yacimiento inédito Neo-Eneolitico en La Rioja. Cuadernos de Investigación (Historia), IX, fasc. 1. Logroño. pp. 39-44.

33. BARANDIARAN, I., 1978: La Atalayuela: fosa de inhumación colectiva del Eneolitico en el Ebro Medio. Príncipe de Viana 152, 153. Pamplona. pp. 381-422.

34. CAVA, A., 1984: La industria... ob. cit. p. 139. PEREZ ARRONDO, C.L. y LOPEZ DE CALLE, C., 1986: Aportaciones... ob. cit. pp. 134-139. 
rios en la fase caracterizada por los microlitos geométricos, cuando presumiblemente formaron un conjunto con significado propio, resultado de la emulación y sentido de competición entre grupos, como quiere Renfrew ${ }^{35} \mathrm{o}$, en términos más generales, de la integración de los sepulcros en un espacio de connotaciones y significado muy especiales.

Detrás de esta variación en la dinámica de ocupación de los monumentos se esconde un complejo proceso de transformaciones en la concepción de lo funerario que llevará, en la estación megalítica de Viguera, a la aceptación de un sepulcro y el rechazo de otros. Por encima de esta desconexión entre las intencionalidades de constructores y últimos usuarios de los megalitos, debemos resaltar la continuidad de una tradición que convierte al sepulcro en depositario no sólo de inhumaciones distanciadas cronológicamente por siglos, sino de creencias y actitudes muy diferentes.

35. RENFREW, C., 1984: Arqueología Social de los monumentos megaliticos. Investigación y Ciencia n. 88 . Barcelona. pp. 70-79. 


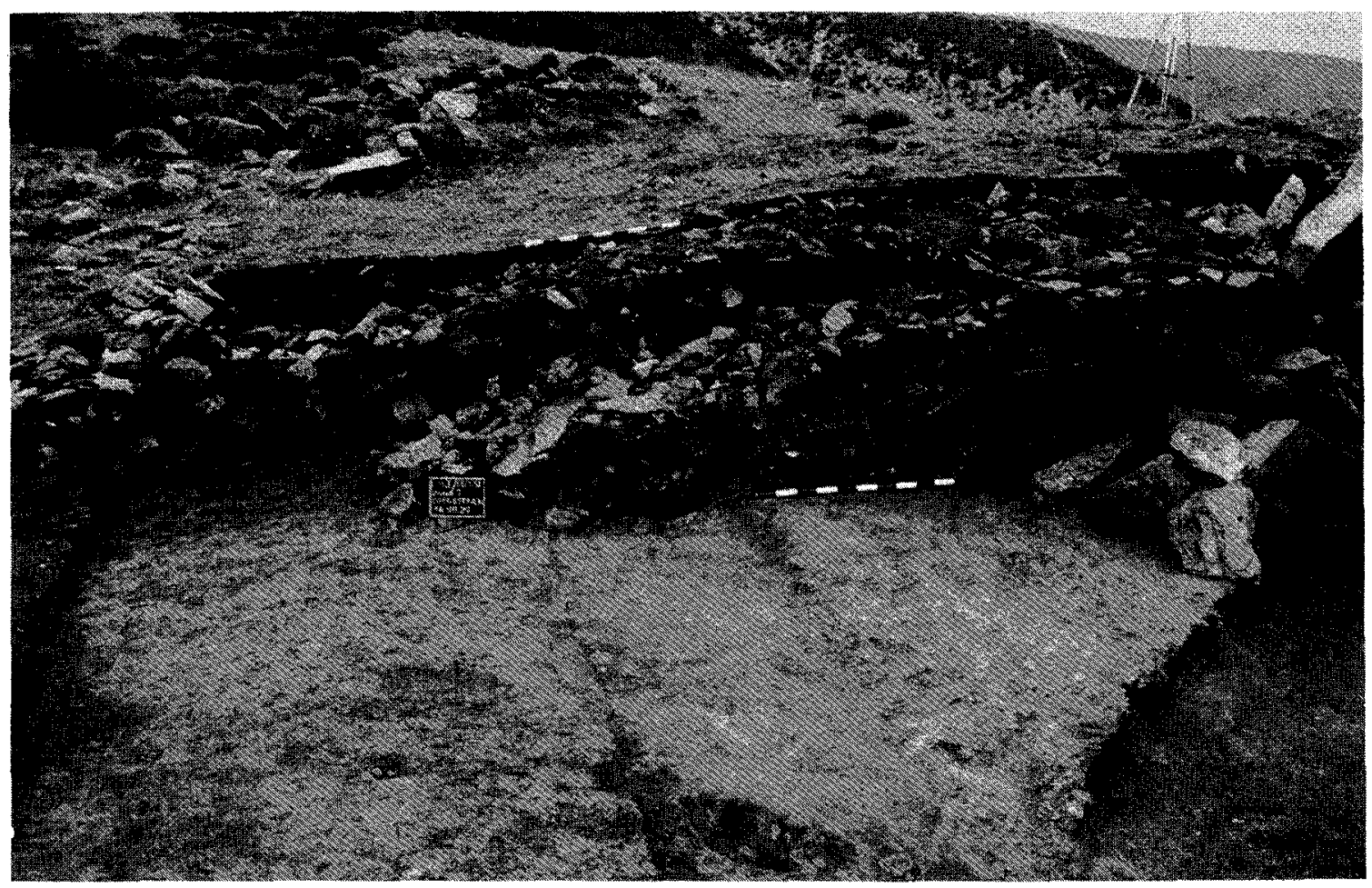

Foto 1. Estratigrafía del túmulo 